NOTICE: this is the author's version of a work that was accepted for publication in Radiation Physics and Chemistry. Changes resulting from the publishing process, such as peer review, editing, corrections, structural formatting, and other quality control mechanisms may not be reflected in this document. Changes may have been made to this work since it was submitted for publication. A definitive version was subsequently published in Radiation Physics and Chemistry, Vol. 85 (2013). DOI: 10.1016/j.radphyschem.2012.12.021 


\title{
A comparative study of $X$-ray shielding capability in ion-implanted acrylic and glass
}

\author{
N.Z. Noor Azman ${ }^{\mathrm{a}, \mathrm{b}}$, S.A. Siddiqui ${ }^{\mathrm{a}}$, M. Ionescu ${ }^{\mathrm{c}}$ and I.M. Low ${ }^{\mathrm{a}^{*}}$ \\ ${ }^{a}$ Department of Imaging and Applied Physics, Curtin University,Perth, Western Australia 6845, \\ Australia. \\ ${ }^{b}$ School of Physics, Universiti Sains Malaysia, Penang, 11800 Malaysia. \\ ${ }^{c}$ Australian Nuclear Science and Technology Organization, Sydney, NSW 2232, Australia. \\ *Corresponding author: j.low@curtin.edu.au; Tel: +618-9266 7544; Fax: +618-9266 2377
}

\begin{abstract}
Samples of acrylic and glass were implanted with tungsten (W) and lead $(\mathrm{Pb})$ to investigate their X-ray attenuation characteristics. The near-surface composition depth profiles of ionimplanted acrylic and glass samples were studied using ion-beam analysis (Rutherford backscattering spectroscopy - RBS). The effect of implanted ions on the X-ray attenuation ability was studied using a conventional laboratory X-ray machine with X-ray tube voltages ranging from $40-100 \mathrm{kV}$ at constant exposure $10 \mathrm{mAs}$. The results were compared with previous work on ion-implanted epoxy. As predicted, the RBS results and X-ray attenuation for both ionimplanted acrylic and glass increase with the type of implanted ions when compared to the controls. However, since the glass is denser than epoxy or acrylic, it has provided the higher Xray attenuation property and higher RBS ion concentration implanted with a shorter range of the ion depth profile when compared to epoxy and acrylic. A prolonged time is necessary for implanting acrylic with a very high nominal dose to minimize a high possibility of acrylic to melt during the process.
\end{abstract}

Keywords: sample matrix, nominal dose, RBS ion concentration, depth profile, implanted ions, $\mathrm{X}$-ray linear attenuation coefficient.

\section{Introduction}

Hitherto, the application of ion implantation has become increasingly used due to the capability of accurate control on the number of implanted ions and the implanted depth distribution profile. This enables scientists to further improve the X-ray absorption capacity of shielding materials such as glass and polymers (Anders, 1997; Chen et al., 2001; Dworecki et al., 2004; Evans et al., 1995; Hubler, 1981; Kozlov et al., 2002; Lee et al., 1993; Lopatin et al., 1998; Soares et al., 2004; Wu et al., 2000; Yuguang et al., 2000). For example, a recent research by Rodriguez, et al. (Rodríguez et al., 2007) has shown that ion implantation is an effective technology for implanting elements into polymers for surface modification to improve their mechanical properties such as hardness and elastic modulus. In addition, promising material comprising $\mathrm{Cu}$ nanoparticles in a $\mathrm{ZnO}$ matrix for exhibiting the phenomenon of self-defocusing and possessing a high nonlinear absorption coefficient for the usage as an active light intensity limiter in the visible spectral range was successfully obtained by the ion implantation technique by Stepanov et al. (Stepanov et al., 2004). Furthermore, our previous work on epoxy implanted with lead, tungsten and gold ions showed a higher x-ray attenuation of when compared to pure epoxy (Noor Azman et al., 2012). 
Glass is one example of materials used in shielding of ionizing radiations, especially for Xrays and gamma-rays, but it is heavy, expensive and very brittle. So, it is not surprising that the application of polymers in X-ray shielding technology is increasing steadily. This is due to a number of advantages that glass could not meet because of their unique properties, such as low manufacturing cost and rugged shatter-resistant material (Dworecki et al., 2004; Soares et al., 2004). But due to its high density as compared to polymer, glass is still in use for ionizing radiation shielding purposes since it can provide higher attenuation than polymer of the same thickness (Chanthima et al., 2011)

The aim of the present work was to synthesize, characterize and compare the x-ray attenuation properties and near-surface composition profiles of acrylic and glass implanted with tungsten and lead for X-ray shielding purposes. These results were also compared with our previous work done on ion-implanted epoxy (Noor Azman et al., 2012).

\section{Materials and Methods}

The works of ion-implantation and the ion beam analysis by Rutherford Backscattering Spectroscopy (RBS) was conducted at Australian Nuclear Science and Technology Organization. As a continuation of our study to improve the X-ray shielding materials, we used here as base materials a commercial acrylic and a commercial glass. Both these materials were implanted with tungsten and lead. For reasons of comparing all different materials, we used the same nominal doses that were used in our previous work on ion-implanted epoxy, which for tungsten $(\mathrm{W})$ was $\left(7 \times 10^{14}\right.$ ions $\left./ \mathrm{cm}^{2}\right)$ and for lead $(\mathrm{Pb})$ was between $\left(7 \times 10^{14}\right.$ ions $\left./ \mathrm{cm}^{2}\right)$ and $\left(1.4 \times 10^{15}\right.$ ions $/ \mathrm{cm}^{2}$ ) in order to prevent possible melting and/or decomposition of the polymer sample matrix during implantation. The ions were produced by a metal evaporation and a direct extraction ion source. The charge distribution of positive ions of $\mathrm{W}$ and $\mathrm{Pb}$ as measured previously by RBS are: $\mathrm{W}^{+1}=1 \%, \mathrm{~W}^{+2}=16 \%, \mathrm{~W}^{+3}=58 \%, \mathrm{~W}^{+4}=25 \%$, and $\mathrm{Pb}^{+1}=35 \%, \mathrm{~Pb}^{+2}=$ $64 \%, \mathrm{~Pb}^{+3}=1 \%$ which are nearly the same as the theoretical prediction by the Debye - Huckel approximation of non-ideal plasma (Anders, 1997). The RBS measured values of the charge distribution provided an average charge of $\mathrm{W}^{+3.07}$ and $\mathrm{Pb}^{+1.66}$ With these values and the nominal acceleration voltage of $40 \mathrm{kV}$ used in this study, an average implantation energy of $\mathrm{W}=122.8$ $\mathrm{keV}$ and $\mathrm{Pb}=66.4 \mathrm{keV}$ was afforded to the ions prior to implantation. The beam size was close to $20 \mathrm{~cm}^{2}$, and the beam current used in this experiment was around $30 \mu \mathrm{A}$. The ion fluence was monitored by converting the ion target current into pulses using a current-to-frequency convertor.

A beam of $1.8 \mathrm{MeV} \mathrm{He}{ }^{+1}$ ions beam was used for RBS, and the information gathered was processed with SIMNRA code (Mayer, 1999) to obtain the calculation of the depth distribution of implanted species, which was then converted in concentration [at\%]. These results were compared with the previous results on ion-implanted epoxy samples (Noor Azman et al., 2012).

For the work on the X-ray shielding capability of these implanted samples, a general diagnostic X-ray machine (Make: Shimadzu, Model: Circlex 0.6/1.2 P364DK-100SF), a DIADOS diagnostic detector and a DIADOS diagnostic dosimeter (PTW-Freiburg, Germany) were used. The DIADOS dosimeter is a universal dosimeter for measuring simultaneous dose and dose rate for radiography, fluoroscopy, mammography, dental X-ray and CT with a minimal dose sensitivity of 0.01 microRoentgen $(\mu R)$. The incident $x$-ray dose $\left(D_{0}\right)$ was measured by 
placing the detector directly below the x-ray tube at a distance of $100 \mathrm{~cm}$. The exit dose (D) was measured by placing the sample on the detector. The x-ray beam was well collimated to the size of the sample and the exposure was set at $10 \mathrm{mAs}$ to receive significant readings for this type of detector. The range of $x$-ray tube voltage $(40-100 \mathrm{kV})$ was selected for this investigation since this range is the normal range of $\mathrm{x}$-ray tube voltage used for the general diagnostic imaging purposes. The linear attenuation coefficient, $\mu$ (unit: $\mathrm{cm}^{-1}$ ) for each sample was determined from Eq. (1) where $x$ is the thickness of the sample.

$$
\mu=\frac{\ln \left(\frac{D_{O}}{D}\right)}{x}
$$

\section{Results and discussion}

The list of samples implanted with different ions is shown in Table 1. Fig. 1 shows the RBS results plotted as the yield versus channel number for acrylic and glass samples (B1-C3) implanted with $\mathrm{W}$ and $\mathrm{Pb}$.

The RBS composition of acrylic and glass was used to calculate the range of implanted ions, using Monte Carlo simulation (SRIM 2010). The range of $122.8 \mathrm{keV} \mathrm{W}$ in acrylic is $84 \mathrm{~nm}$ and in glass is $48 \mathrm{~nm}$, and the range of $66.4 \mathrm{keV} \mathrm{Pb}$ in acrylic is $56 \mathrm{~nm}$ and in glass is $32 \mathrm{~nm}$. These values are similar with the depth distribution calculated from RBS results and shown in Fig. 2, where for comparison reasons we also show the results of depth distribution of $\mathrm{W}$ and $\mathrm{Pb}$ in epoxy.

The results confirmed that the range of implanted ions is inversely proportional with the atomic number $(Z)$ of implanted ion $(\mathrm{Pb}=82, \mathrm{~W}=74)$ and with the density of the matrix. In addition, RBS shows specific variations in range and concentration of implanted ions, which are the result of specific sample matrix inhomogeneity. For example (Fig. 2), for W-implanted acrylic (B1), a maximum $\mathrm{W}$ concentration of 0.05 at.\% has been implanted down to a depth of about 1,000 mono layers (ML) and then it drops to about 0.025 at.\% for the next $200 \mathrm{ML}$. For $\mathrm{W}$-implanted glass (C1), a maximum $\mathrm{W}$ concentration of 0.1 at.\% has been implanted down to a depth of about 1,000 ML, and as the density of glass is higher than the density of acrylic, one would expect the $\mathrm{W}$ implantation depth to be smaller than the $\mathrm{W}$ implantation depth in acrylic, but this is not the case due to local inhomogeneities. Even for the same sample matrix (acrylic), the same ion may have a different depth profile, and this again, is attributed to the differences in the local density of the acrylic itself. Similar depth profile RBS results were also obtained for composite samples of glass as a matrix base and also our previously epoxy samples (Noor Azman et al., 2012).

In Table 1, the differences between the measured RBS concentration of $\mathrm{W}$ and $\mathrm{Pb}$ ion at the same nominal implantation dose are explained by two factors: the different sputtering properties of the two ions, and the uncertainty in the dose measurement between different implantation

runs. The glass is a denser $\left(2.45 \mathrm{~g} / \mathrm{cm}^{3}\right)$ matrix when compared to the acrylic or epoxy and contains heavier elements $(\mathrm{Si}, \mathrm{Na})$ hence it has a higher stopping power to slow down the ions as they travel within it. Further, a denser material has a lower projected range/depth profile 
(because ions have a greater chance of colliding with the atoms within the material especially near the surface). In contrast, epoxy and acrylic have nearly the same density (average 1.15 $\mathrm{g} / \mathrm{cm}^{3}$ ) and hence they do not show significant differences in the RBS concentration between them. These statements are supported by the results in Fig. 2 since Pb-implanted glass (C3) has a shorter depth profile as compared to $\mathrm{Pb}$-implanted epoxy (A3) and Pb-implanted acrylic (B3) of the same nominal dose of $\mathrm{Pb} 1.4 \times 10^{15}$ ions $/ \mathrm{cm}^{2}$.

Besides, there is a huge difference in ion concentration between sample A3 or B3 with C3 when we double the nominal dose $\left(1.4 \times 10^{15}\right.$ ions $\left./ \mathrm{cm}^{2}\right)$ as shown in Table 1 . After the ions entering a matrix, the energy that an ion loses is converted to heat when slowing down within the material as the atoms dissipate the kinetic energy in a series of collisions. Moreover, the melting point of acrylic or epoxy is $\sim 160{ }^{\circ} \mathrm{C}$ while for the glass is $>1000{ }^{\circ} \mathrm{C}$. So there is a high possibility of acrylic being altered (Fig. 3) by the energetic ions (with average velocity around $2.0 \times 10^{5} \mathrm{~m} / \mathrm{s}$ ) when they bombard the surface and cause bond breaking along the ion tracks, some of the matrix atoms $(\mathrm{H}, \mathrm{O})$ could be lost and escape by diffusion. These altered regions of the polymer may play an additional role in absorbing the X-ray, but this is yet to be tested in a future experiment.

Fig. 4 shows the linear attenuation coefficient, $\mu$ as a function of $\mathrm{X}$-ray tube voltage for all samples listed in Table 1, and for non-implanted samples of each material used for ion implantation. The result of $\mu$ for $\mathrm{W}$ - implanted acrylic and glass with the nominal dose of $7.0 \mathrm{x}$ $10^{14}$ ions $/ \mathrm{cm}^{2}$ is nearly the same with the result of $\mu$ for non-implanted material, at each X-ray tube voltage. Meanwhile, with the decreasing of $\mu$ with the increasing of X-ray tube voltage we noticed that $\mu$ is also increasing with the atomic number of implanted element. For the same Xray tube voltage, the heavier the implanted ion or in other words the higher the atomic number of implanted ion, the higher is the value of $\mu$ and can be differentiated from the $\mu$ for pure matrix composite especially at lower X-ray tube voltage $(40-70 \mathrm{kV})$. This showed that the attenuation of the primary $\mathrm{x}$-ray beam by the absorbing material is highly dependent on the atomic number of the absorbing material itself. Notice that the atoms of higher atomic number absorbing material present larger targets for the radiation to strike and hence the chances of interactions via the photoelectric interaction is relatively high. Hence, the attenuation should therefore be relatively large. Meanwhile, in the case of lower atomic number absorbing material however the individual atoms are smaller and hence the chances of interactions are reduced. In other words the radiation has a greater probability of being transmitted through the absorbing material and the attenuation is consequently lower than in the high atomic number case. The photoelectric interaction usually dominates in the lower X-ray energy range and also for the high atomic number of absorbing material (implanted ions). The probability for the photoelectric interaction to occur is dependent on $\mathrm{Z}^{3} / \mathrm{E}^{3}$ where $\mathrm{Z}$ is the atomic number of the absorbing material, and $\mathrm{E}$ is the photon (X-ray / gamma-ray) energy(Sprawls, 1993). Additionally, the ionimplanted glass shows the highest attenuation compared to acrylic/epoxy since it is denser and has the highest RBS ion concentration of the same ion (Fig. 5) because more primary x-ray beam being attenuated by a denser absorbing material than a lower density absorbing material since the chances of an interaction between the radiation and the atoms of the absorbing material are relatively higher. In most cases, high density absorbing materials are more effective than low density alternatives for blocking or reducing the intensity of radiation. 
However, low density absorbing materials can compensate for the disparity with increased thickness, which is as significant as density in shielding applications.

From the above analyses, glass is still the best candidate for implanting with high RBS ion concentration and thus able to attenuate more X-rays as compared to pure acrylic/epoxy but it is fragile and easy to break; thus we need to handle it carefully for using as X-ray shielding. In contrast, even though acrylic is inferior in terms of density, melting point and seems not an ideal applicant but an implanted acrylic can still be chosen as a candidate for X-ray shielding because it is tougher and lighter as compared to glass but prolonged time is needed when implanted it with a high nominal dose to prevent it to melt during the implantation process. Besides, it also can provide similar $\mathrm{x}$-ray attenuation like glass with increased thickness, which is as significant as density in shielding applications.

\section{Conclusions}

Ion-implantation has been successfully used to modify the near-surface of acrylic and glass with $\mathrm{W}$ and $\mathrm{Pb}$ ions to improve $\mathrm{X}$-ray attenuation for X-ray shielding for diagnostic radiology purposes. The X-ray attenuation is higher for the composite with the denser sample matrix and the composite having the higher RBS ion concentration. However, the amount of implanted doses will need to be significantly increased so that this approach can be feasible for designing new shielding materials for the X-ray technologists. Even though glass provided the best results for both RBS ion concentration and X-ray attenuation, its usage as X-ray shielding needs extra care since it is easy to break. In contrast, implanted acrylic can be a good candidate for X-ray shielding but much time is needed when implanted acrylic with a very high nominal dose since it has a low melting point and by increasing its thickness.

\section{Acknowledgements}

The work on ion-implantation and ion-beam analysis was conducted at the Australian Nuclear Science and Technology Organization with financial support from AINSE (AINGRA 11-135).

\section{References}

Lead x-ray glass vs. lead plastic acrylic. MarShield available online http://www.marshield.com/nuclear-shielding/leaded-x-ray-shielding-glass-and-acrylic (5 May 2011).

Anders, A., 1997. Ion charge state distributions of vacuum arc plasmas: The origin of species. Physical Review E 55, 969-981.

Chanthima, N., Kaekwkhao, J., Kedkaew, C., Chewpraditkul, W., Pokaipisit, A., Limsuwan, P., 2011. Study on interaction of $\mathrm{Bi} 2 \mathrm{O} 3, \mathrm{PbO}$ and $\mathrm{BaO}$ in silicate glass system at $662 \mathrm{keV}$ for development of gamma-rays shielding materials. Progress in Nuclear Sicence and Technology 1, 106-109.

Chen, J.S., Lau, S.P., Sun, Z., Tay, B.K., Yu, G.Q., Zhu, F.Y., Zhu, D.Z., Xu, H.J., 2001. Structural and mechanical properties of nitrogen ion implanted ultra high molecular weight polyethylene. Surface and Coatings Technology 138, 33-38. 
Dworecki, K., Drabik, M., Hasegawa, T., Wąsik, S., 2004. Modification of polymer membranes by ion implantation. Nuclear Instruments and Methods in Physics Research Section B: Beam Interactions with Materials and Atoms 225, 483-488.

Evans, P.J., Hyvarinen, J., Samandi, M., 1995. Surface modification of austenitic stainless steel by titanium ion implantation. Surface and Coatings Technology 71, 151-158.

Hubler, G.K., 1981. Use of ion beam analysis in metal modification by means of ion implantation. Nuclear Instruments and Methods in Physics Research 191, 101-113.

Kozlov, E.V., Ryabchikov, A.I., Sharkeev, Y.P., Stepanov, I.B., Fortuna, S.V., Sivin, D.O., Kurzina, I.A., Prokopova, T.S., Mel'nik, I.A., 2002. Formation of intermetallic layers at high intensity ion implantation. Surface and Coatings Technology 158-159, 343-348.

Lee, E.H., Rao, G.R., Lewis, M.B., Mansur, L., K., 1993. Ion beam application for improved polymer surface properties. . Nuclear Instruments and Methods in Physics Research Section B: Beam Interactions with Materials and Atoms 74, 326-330.

Lopatin, C.M., Alford, T.L., Pizziconi, V.B., Kuan, M., Laursen, T., 1998. Ion-beam densification of hydroxyapatite thin films. Nuclear Instruments and Methods in Physics Research Section B: Beam Interactions with Materials and Atoms 145, 522-531.

Mayer, M., 1999. Proceedings of the 15th International Conference on the Application of Accelerators in Research and Industry, J. L. Duggan and I.L. Morgan (eds.), American Institute of Physics Conference Proceedings 475, 541.

Noor Azman, N.Z., Siddiqui, S.A., Ionescu, M., Low, I.M., 2012. Synthesis and characterisation of ion-implanted epoxy composites for X-ray shielding. Nuclear Instruments and Methods in Physics Research Section B: Beam Interactions with Materials and Atoms 287, 120-123.

Rodríguez, R.J., Medrano, A., García, J.A., Fuentes, G.G., Martínez, R., Puertolas, J.A., 2007. Improvement of surface mechanical properties of polymers by helium ion implantation. Surface and Coatings Technology 201, 8146-8149.

Soares, M.R.F., Alegaonkar, P., Behar, M., Fink, D., Müller, M., 2004. 6Li+ ion implantation into polystyrene. Nuclear Instruments and Methods in Physics Research Section B: Beam Interactions with Materials and Atoms 218, 300-307.

Sprawls, P., 1993. The Physical Principles of Medical Imaging, 2nd edition ed. Aspen Publishers, Gaithersburg, Md.

Stepanov, A.L., Khaibullin, R.I., Can, N., Ganeev, R.A., Ryasnyansky, A.I., Buchal, C., Uysal, S., 2004. Application of ion implantation for synthesis of copper nanoparticles in a zinc oxide matrix for obtaining new nonlinear optical materials. Tech. Phys. Lett. 30, 846-849.

Wu, Y., Zhang, T., Zhang, H., Zhang, X., Deng, Z., Zhou, G., 2000. Electrical properties of polymer modified by metal ion implantation. Nuclear Instruments and Methods in Physics Research Section B: Beam Interactions with Materials and Atoms 169, 89-93.

Yuguang, W., Tonghe, Z., Huixing, Z., Xiaoji, Z., Zhiwei, D., 2000. Polymer modification by MEVVA source deposited and ion implantation. Surface and Coatings Technology 131, 520524. 


\section{List of figure captions:}

1. RBS result for (a) acrylic implanted samples $\mathrm{B} 1$ (W), B2 and $\mathrm{B} 3(\mathrm{~Pb})$; and (b) glass implanted samples $\mathrm{C} 1(\mathrm{~W}), \mathrm{C} 2$ and $\mathrm{C} 3(\mathrm{~Pb})$.

2. RBS depth profile of implanted elements, for samples listed in Table 1. For comparison reasons we included the previous results on epoxy.

3. SEM image of the surface of a) acrylic implanted with $\mathrm{Pb}$ (sample B3) showing the region being melted during the higher nominal dose of implantation; and b) glass implanted with $\mathrm{Pb}$ (sample C3).

4. Comparison of $\mu$ versus X-ray tube voltage for (a) pure acrylic and acrylic implanted samples B1 (W), B2 and B3(Pb); and (b) pure glass and glass implanted samples $\mathrm{C} 1(\mathrm{~W})$, $\mathrm{C} 2$ and $\mathrm{C} 3(\mathrm{~Pb})$.

5. Comparison of $\mu$ versus $\mathrm{X}$-ray tube voltage for (a) W-implanted epoxy (A1), acrylic (B1) and glass (C1); (b) Pb-implanted epoxy (A2), acrylic (B2) and glass (C2); and (c) Pbimplanted epoxy (A3), acrylic (B3) and glass (C3). 
Table 1

List of polymer composites and glass prepared with different implanted ions and their concentrations. For comparison reasons, we included previous results on the epoxy.

\begin{tabular}{ccccc} 
Sample ID & Matrix & $\begin{array}{c}\text { Nominal dose } \\
{\left[\text { ions } / \mathrm{cm}^{2}\right]}\end{array}$ & Implanted Ion & $\begin{array}{c}\text { RBS ion concentration } \\
{[\text { at. \% }]}\end{array}$ \\
\hline A1 & $7.0 \times 10^{14}$ & $\mathrm{~W}$ & 0.055 \\
$\mathrm{~A} 2$ & Epoxy & $7.0 \times 10^{14}$ & $\mathrm{~Pb}$ & 0.250 \\
$\mathrm{~A} 3$ & $1.4 \times 10^{15}$ & $\mathrm{~Pb}$ & 0.390 \\
\hline $\mathrm{B} 1$ & $7.0 \times 10^{14}$ & $\mathrm{~W}$ & 0.050 \\
$\mathrm{~B} 2$ & $7.0 \times 10^{14}$ & $\mathrm{~Pb}$ & 0.200 \\
$\mathrm{~B} 3$ & Acrylic & $1.4 \times 10^{15}$ & $\mathrm{~Pb}$ & 0.430 \\
$\mathrm{C} 1$ & & $7.0 \times 10^{14}$ & $\mathrm{~W}$ & 0.100 \\
$\mathrm{C} 2$ & & $7.0 \times 10^{14}$ & $\mathrm{~Pb}$ & 0.290 \\
$\mathrm{C} 3$ & Glass & $1.4 \times 10^{15}$ & $\mathrm{~Pb}$ & 0.850 \\
\hline
\end{tabular}

